\begin{abstract}
VERSITA 10.2478/v10310-012-0006-5
Ovidius University Annals of Chemistry

Volume 23, Number 1, pp.41-46, 2012
\end{abstract}

\title{
Fatty acid composition of Bulgarian Black Sea fish species
}

\author{
Albena MERDZHANOVA*, Mona STANCHEVA and Lubomir MAKEDONSKI \\ Department of Chemistry, Medical University of Varna, 55 Marin Drinov Str., 9002 Varna, Bulgaria
}

\begin{abstract}
The fatty acid compositions of three Black Sea fish species turbot (Pseta maxima), red mullet (Mullus barbatus ponticus) and garfish (Belone belone) were investigated. This species are considered as preferred for consumption in Bulgaria. Lipid extraction was done according to the Bligh and Dyer method. The fatty acid composition was determined by GC/MS. The saturated fatty acids amounts were $38.32 \%$ for turbot, $35.44 \%$ red mullet and $42.90 \%$ for garfish. Monounsaturated fatty acids were found in lowest level in comparison with other groups for garfish (23.65\%) and turbot $(24.85 \%)$ while for red mullet they have a highest value $-37.56 \%$. Omega 3 polyunsaturated fatty acids as eicosapentaenoic (C 20:5 omega 3, EPA) and docosahexaenoic (C 22:6 omega 3, DHA) acids were found in highest levels in turbot $(22.26 \%)$ and garfish $(21.80 \%)$ and in lowest values of red mullet (9.35\%). The results showed that the fish examined are good source of omega 3 polyunsaturated fatty acids, resulting in a very favourable omega 3 / omega 6 ratios, especially in turbot and garfish.
\end{abstract}

Keywords: Black Sea fish, fatty acids, PUFA, GC/MS

\section{Introduction}

Many marine fish are well known to be excellent dietary sources of essential fatty acids such as omega 3 polyunsaturated fatty acids (n-3 PUFA). The data obtained in epidemiological and experimental studies supported beneficial activity of these PUFA especially omega 3 (n-3) such as EPA and DHA in the prevention of human cardiovascular diseases and cancers, lowering of incidents of diabetes, they play a vital role in the development and function of nervous system $[1,2]$. Considering all these facts the importance of consuming fish rich in omega 3 (n-3) and omega 6 (n-6) PUFA can be taken into consideration. The WHO / FAO recommendations for total daily diet the $n-6 / n-3$ ratio should be from 1:1 to $5: 1$ [3].

In Bulgaria the consumption of fish is very low (4.5kg annual per capita) compared with the average European levels (23 kg annual per capita) [4].

From the Black Sea fisheries perspective, the most important demersal fish species are turbot (Psetta maxima) and red mullets (Mullus barbatus). Turbot and red mullet are distributed all over the shelf of Black Sea. Turbot is a very large, broad bodied, left-eyed flatfish. It is a benthic marine species, living on sandy and muddy bottoms, from shallow waters to $110 \mathrm{~m}$. Turbot migrations are relative short and perpendicular on shore. Turbot is a high-value species and its white meat with low lipid levels is appreciated by consumers. In all Black Sea countries turbot is one of the most valuable fish species [5].

In the waters of Bulgaria and Romania red mullet is not important target for fisheries but due to its taste it is preferred for consumption. It prefers waters with the temperature higher $8^{\circ} \mathrm{C}$ and salinity more than $17 \%$ o [5].

Garfish is an epipelagic migratory species that is widely distributed in the North-Eastern Atlantic, Mediterranean as well as the Black Sea and is generally considered of minor commercial importance. Three subspecies have been recognized: first restricted to the North-Eastern Atlantic, second distributed from the south of France in the Mediterranean Sea to the Canary Islands in the Atlantic and B. belone euxini - which is found in the Black Sea and the Sea of Azov. Garfish are mainly found in offshore areas except for the spawning period when they migrate into coastal regions where they are also susceptible to commercial exploitation [6]. 
However information about the fatty acids (FA) composition of these Bulgarian Black Sea fish species is lacking.

The aims of our study are to determinate total lipids and fatty acid composition and collect information about these valuable and delicious fishes.

\section{Experimental}

\subsection{Sampling of fish species}

The samples of three Bulgarian fish species turbot (Psetta maxima), red mullet (Mullus barbatus ponticus) and garfish (Belone belone) were purchased from Varna local fish market during 2009. Their total lipids and fatty acid compositions were compared. The samples were immediately frozen at $-20^{\circ} \mathrm{C}$ and whole stored in a fridge. Biometrical characteristics and total lipids content were determined and noted (Table 1). Prior to analysis the edible fish tissue was filleted with the skin left on and homogenized using kitchen homogenizer.

\subsection{Lipid extraction}

Prior to analysis, the head, tail, fins, and viscera of the fish were removed. The raw edible fish tissue was extracted by the method of Blight and Dyer [7] using chloroform/methanol/water in a ratio 2:2:1. After phase separation, the chloroform extracts were evaporated until dryness. The total lipid content was determined gravimetrically for each fish species in triplicate. The results were expressed as g per $100 \mathrm{~g}$ raw tissue (g $100 \mathrm{~g}^{-1}$ r.t.).

\subsection{Fatty acids analysis}

Fatty acid compositions of total lipids at edible fish tissue were determined by GC of the corresponding methyl esters. The residual lipid fraction was methylated by base-catalyzed transmethylation using $2 \mathrm{M}$ methanolic potassium hydroxide and n-hexane according to BDS EN 5509:2000 [8]. After 10 minutes centrifugation (3500 rps), the hexane layer was taken for GC analyses. Gas chromatography was performed by a model FOCUS Gas Chromatograph with autosampler A 3000, equipped with Polaris Q MS detector (Thermo Scientific, USA). The capillary column used was a TR-5 MS (Thermo Scientific, USA) universal column $30 \mathrm{~m}$ length and $0.25 \mathrm{~mm}$ i.d, with a wide range of applications from food analysis. Helium was used as a carrier gas at flow rate $1 \mathrm{ml} / \mathrm{min}$. Chromatographic separation was achieved by temperature range: initial temperature $40^{\circ} \mathrm{C}$ for 4 min followed by $10^{\circ} \mathrm{C}$ per minute until $235^{\circ} \mathrm{C}$ and final temperature reach was $280^{\circ} \mathrm{C}$ for 5 min. The sample volume was $1 \mu \mathrm{l}$. The three parallel analyses were made from each methanolysed sample. The injector was a split/splitless injector operated in the split mode. Peaks were identified according to two parameters: Retention Time (RT) based on available FAME mix standard (SUPELCO F.A.M.E. Mix C4-C24) and mass spectra (ratio m/z) - compared to internal Data Base (Thermo Sciences Mass Library, USA). FAMEs was identified and quantified by comparison with the RT and peak areas of SUPELCO standards. Three replicate GC analyses were performed. The values of FA were expressed as percentage of total FA mass as a mean value and \pm standard deviation (SD) [9]. All of the chemicals used in the experiments were analytical grade and GC grade (Sharlau, Sharlab Sourcing Group, Spain).

\subsection{Statistical analysis}

The results of analysis are presented as mean values \pm standard deviation (SD). Column statistics was used for calculation of the means and standard deviations. Student's t-test was used to evaluate the differences between the means. Statistical significance was indicated at $\mathrm{p}<0.05$. Statistical analysis was done using GrapgPad Prizm 5, USA software.

\section{Results and Discussions}

\subsection{Total lipids}

Fish are usually classified into groups according to their overall lipid content including lean $(<2 \%)$, low-fat $(2-4 \%)$, medium-fat $(4-8 \%)$ and high-fat $(>8 \%)[10]$. The present study showed that 
garfish (2.92g per $100 \mathrm{~g}$ raw tissue) and red mullet (5.38 g per $100 \mathrm{~g}$ raw tissue) are classified amongst those fish with medium-fat to highly fat fish whereas turbot presented lowest total lipids value $-1.51 \mathrm{~g}$ per $100 \mathrm{~g}$ raw tissue and can named as lean species (Table 1).

Table 1. Biometric characteristics and total lipids content (mean $\pm \mathrm{SD})$

\begin{tabular}{|l|r|r|r|}
\hline Parameter & $\begin{array}{c}\text { Red mullet } \\
\mathrm{n}=12\end{array}$ & $\begin{array}{c}\text { Turbot } \\
\mathrm{n}=3\end{array}$ & \multicolumn{1}{c|}{$\begin{array}{c}\text { Garfish } \\
\mathrm{n}=6\end{array}$} \\
\hline Total lipids $(\mathrm{g}$ & $5.38 \pm 0.40$ & $1.51 \pm 0.05$ & $2.92 \pm 0.25$ \\
$100 \mathrm{~g}^{-1}$ r.t. $)$ & & & \\
\hline Mean weight $(\mathrm{g})$ & $35.0 \pm 5.0$ & $1400.0 \pm 150.0$ & $55.0 \pm 5.0$ \\
Mean length $(\mathrm{cm})$ & $15.0 \pm 1.5$ & $45.0 \pm 5.0$ & $35.0 \pm 2.0$ \\
\hline Habitat & Demersal & Demersal & Pelagic \\
\hline Food habits & Carnivorous & Carnivorous & Carnivorous \\
\hline
\end{tabular}

\section{$n$ - number of specimens}

$S D$ - standard deviation

The variations of the fish tissue lipid content are related with different factors as seasons, water temperature, feeds. [10]. Guner et al. and Tanakol et al. presented significant higher amounts for garfish and close for grey mullet than our data. [11,12]. Polat et al. found the similar total lipids values for Mediterranean red mullet [13]. The results for lipid values for Black Sea turbot and for farmed turbot are similar to our data $[12,14]$. In general the lipid content reported for investigated Black Sea fish species were in agreement with the average lipid value presented for these fish species in literature [11-17].

\subsection{Fatty acid composition}

The twenty - eight fatty acids from $\mathrm{C} 12: 0$ to $\mathrm{C}$ 22:6 n-3 were identified and compared among the different species. They was a wide variation and significant differences $(\mathrm{p}<0.05)$ among the fatty acid profiles of fish species in terms of total and individual saturated and unsaturated FAs. A lipid analysis enabled the classification and quantitative determination of FA as well as the sum of saturated fatty acids (SFA), monounsaturated fatty acids (MUFA), and polyunsaturated fatty acids (PUFA). In turbot and garfish were observed following FA distribution: SFA > PUFA > MUFA, whereas red mullet presented different allocation of FA groups: MUFA > SFA > PUFA respectively.

Such significantly higher quantities in MUFA compared to PUFA $(\mathrm{p}<0.001)$ and SFA $(\mathrm{p}<0.01)$ were found for red mullet (Fig. 1). A deflection of this pattern was observed for garfish, a medium fatty fish (total lipids $<3$ g. $100^{-1}$ r.t.) in which SFA content was significantly higher than MUFA $(\mathrm{p}<0.001)$ and PUFA ( $\mathrm{p}<0.001)$. The turbot, qualified as a lean fish (total lipids $<2$ g. $100^{-1}$ r.t.), reveals significantly lower MUFA content compared with PUFA $(\mathrm{p}<0.001)$ and SFA $(\mathrm{p}<0.001)$ (Fig. 1). The MUFA is a dominant group in red mullet $(37.56 \%)$ whereas SFA contents in turbot $(38.40 \%)$ and garfish $(42.90 \%)$ were similar. In our study in turbot and garfish we found low MUFA levels.

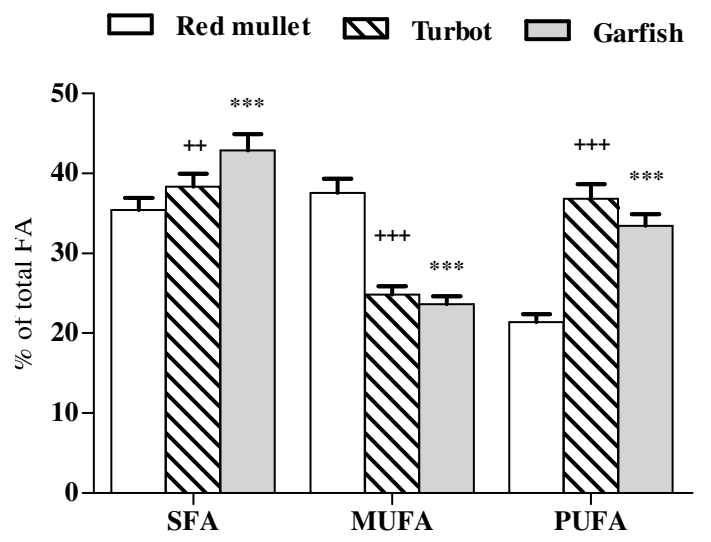

Fig. 1. Comparison of fatty acid groups in Black Sea fish species *** $\mathrm{p}<0.001$ SFA vs PUFA and SFA vs MUFA; $+++\mathrm{p}<0.001$ and $++\mathrm{p}<0.05$ PUFA vs MUFA

The fatty acid profile generally exhibits a dominance of the two classes, SFAs and PUFAs for turbot and garfish while in red mullet MUFAs and SFAs were observed in higher amounts. These results were in agreement with the average FA value presented for these fish species in literature [11-16]. The fatty acids composition of Black sea fish species are given in Table 2 as mean value and \pm standard deviation (as percentage of total amount fatty acid).

\subsubsection{Saturated fatty acid}


The analyzed Black sea fish species present high concentrations of three quantitatively dominating SFA: palmitic (C 16:0), stearic (C 18:0) and myristic (C 14:0) acids witch followed next distributions C 16:0 > C 18:0 > C 14:0.

The dominance of SFAs was mainly due to the high level of $\mathrm{C} 16: 0$ contributing approximately to $60 \%$ of the total SFA content in the examined fish. Garfish contained the highest C16:0 amount $(22.97 \%)$ whereas turbot and red mullet presented lower levels $(21.43 \%$ and $19.92 \%)$. This FA was reported in lower values in turbot from Black sea by Ozogul et al. and in higher quantities in red mullet by Polat et al $[13,14]$.

Table 2. Fatty acids profile in edible fish tissue (mean $\pm \mathrm{SD}$ ) of analyzed species

\begin{tabular}{|c|c|c|c|}
\hline $\begin{array}{l}\text { Fatty } \\
\text { Acid }\end{array}$ & Red mullet & Turbot & Garfish \\
\hline \multicolumn{4}{|c|}{ Saturated fatty acids } \\
\hline C 12:0 & $0.53 \pm 0.02$ & $1.60 \pm 0.20$ & $1.46 \pm 0.16$ \\
\hline C 13:0 & $0.02 \pm 0.01$ & $0.30 \pm 0.01$ & $1.08 \pm 0.05$ \\
\hline C 14:0 & $4.27^{\mathrm{b}} \pm 0.70$ & $2.50^{\mathrm{a}, \mathrm{b}} \pm 0.50$ & $2.67^{\mathrm{a}} \pm 0.25$ \\
\hline C 16:0 & $21.43^{\mathrm{a} . \mathrm{b}} \pm 1.15$ & $19.92^{\mathrm{a}} \pm 1.20$ & $22.97^{\mathrm{a}, \mathrm{b}} \pm 1.58$ \\
\hline C 17:0 & $0.63 \pm 0.02$ & $0.60 \pm 0.05$ & $1.35 \pm 0.50$ \\
\hline C 18:0 & $6.30^{\mathrm{a}} \pm 0.050$ & $7.20^{\mathrm{a}} \pm 0.65$ & $4.16^{\mathrm{a}} \pm 0.84$ \\
\hline C 20:0 & $0.65 \pm 0.02$ & $1.60 \pm 0.15$ & $2.24 \pm 0.26$ \\
\hline C 21:0 & $0.39 \pm 0.01$ & 0.00 & $0.91 \pm 0.03$ \\
\hline C 22:0 & $0.69^{\mathrm{a}} \pm 0.02$ & $1.32 \pm 0.35$ & $2.57^{\mathrm{a}} \pm 0.05$ \\
\hline C 23:0 & $0.37 \pm 0.01$ & $0.81 \pm 0.01$ & $0.19 \pm 0.03$ \\
\hline C 24:0 & $0.65 \pm 0.02$ & $2.47 \pm 0.54$ & $2.60 \pm 0.20$ \\
\hline \multicolumn{4}{|c|}{ Monounsaturated fatty acids } \\
\hline C 14:1 & $2.06 \pm 0.50$ & $2.40 \pm 0.65$ & $1.71 \pm 0.05$ \\
\hline C 16:1 & $9.36^{\mathrm{b}} \pm 1.02$ & $5.81^{\mathrm{a}} \pm 0.73$ & $9.62^{\mathrm{a}} \pm 1.20$ \\
\hline C 17:1 & $0.68 \pm 0.05$ & $0.60 \pm 0.03$ & $0.30 \pm 0.15$ \\
\hline C 18:1 n9 & $20.90^{b} \pm 1.50$ & $10.20^{\mathrm{a}} \pm 1.05$ & $6.75^{a} \pm 0.50$ \\
\hline C 20:1 & $2.06 \pm 0.40$ & $1.30 \pm 0.29$ & $1.34 \pm 0.12$ \\
\hline C 22:1 n9 & $1.85^{\mathrm{b}} \pm 0.40$ & $2.87^{\mathrm{a}} \pm 0.30$ & $2.39^{\mathrm{a}, \mathrm{b}} \pm 0.30$ \\
\hline C 24:1 & $0.50 \pm 0.02$ & $1.61 \pm 0.26$ & $1.28 \pm 0.15$ \\
\hline \multicolumn{4}{|c|}{ Polyunsaturated fatty acids } \\
\hline C 18:3 n6 & $1.57^{\mathrm{a}, \mathrm{b}} \pm 0.10$ & $2.50^{\mathrm{a}} \pm 0.65$ & $1.26^{b} \pm 0.05$ \\
\hline C $18: 2$ n6 & $2.62^{\mathrm{a}} \pm 0.01$ & $2.10^{\mathrm{a}} \pm 0.55$ & $3.47^{\mathrm{a}} \pm 0.45$ \\
\hline C 18:3 n3 & $1.20^{\mathrm{a}} \pm 0.80$ & $0.55^{\mathrm{a}} \pm 0.01$ & $1.96^{\mathrm{a}} \pm 0.20$ \\
\hline C $20: 5 \mathrm{n} 3$ & $1.15^{\mathrm{a}} \pm 0.50$ & $4.60^{\mathrm{a}} \pm 0.68$ & $1.33^{\mathrm{a}} \pm 0.15$ \\
\hline C $20: 4$ n6 & $5.11^{\mathrm{b}} \pm 0.85$ & $4.00^{\mathrm{a}} \pm 0.81$ & $2.67^{\mathrm{a}, \mathrm{b}} \pm 0.20$ \\
\hline C $20: 2$ & $0.96 \pm 0.05$ & $2.37 \pm 0.56$ & $1.15 \pm 0.15$ \\
\hline C $20: 3 \mathrm{n} 3$ & $0.90 \pm 0.05$ & $2.71 \pm 0.55$ & $1.75 \pm 0.05$ \\
\hline C 20:3 n6 & $0.96 \pm 0.03$ & $3.80 \pm 0.80$ & 0.00 \\
\hline C $22: 6$ n3 & $7.01^{\mathrm{a}, \mathrm{b}} \pm 0.97$ & $14.86^{\mathrm{a}} \pm 1.15$ & $18.51^{\mathrm{a}} \pm 1.10$ \\
\hline C $22: 2$ & $0.83 \pm 0.02$ & $0.50 \pm 0.05$ & $0.60 \pm 0.05$ \\
\hline
\end{tabular}

value denote significant differences $(\mathrm{P}<0.05)$ between fish species
The other predominant SFA is C 18:0 varying from $4.16 \%$ (garfish) to $7.20 \%$ (turbot). C 14:0 SFA was found in range from $2.50 \%$ (turbot) to $4.27 \%$ (red mullet). Similar results were reported by Polat et al. for Mediterranean red mullet, Bayir et al. for garfish from Turkish markets and Ozogul et al. for Black Sea turbot $[13,16]$.

\subsubsection{Monounsaturated fatty acid}

The amounts of MUFA's vary significantly especially in wild fish [9]. Red mullet contained the highest MUFA amount due to the highest levels of oleic acid (C18:1 n-9) (20.90\%) which is a 55.6\% from total MUFA's. Turbot presented a twice as low amount- $10.20 \%$, whereas garfish showed just $6.5 \%$ for this acid. Many studies reported that C18:1 n-9 is the main MUFA in seawater fish species, but this fatty acid has exogenous origin and usually reflects the type of diet of the fish $[12,14]$.

The highest value of palmitoleic acid (C16:1 n7) was obtained for garfish $(9.32 \%)$ while turbot present a minimum value $(4.77 \%)$. The Erucic acid present significant levels in all analyzed species ranged from $1.85 \%$ (red mullet) to $2.87 \%$ (turbot).

Ozogul et al. showed that Black sea turbot has C 18:1 n-9 level - up to $13 \%$, while on the other hand C16:1 n-7 concentration - 4.28\%. In contrast, in some Mediterranean and Aegean fish species such as mullet and sardine have a C16:1 n-7 level $17.00 \%$ and $12.00 \%$, respectively while C 18:1 n-9 was only $4.50 \%[14]$. Our previous results for other Black sea fish species also showed higher levels of C16:1 n-7 compared with C 18:1 n-9 [17].

The Black sea is the most isolated European semi-enclosed and costal seas from the deep ocean. The biological consequence of the excess nutrient runoff from incoming rivers is the most intense eutrophication (in the world), thus transforming the Black sea ecosystem. Tanakol et al, supposed that the decline in populations of zooplankton, increasing of phytoplankton mass and other as a response to the eutrophication in the Black sea and the fishes from that region had low levels in some MUFAs as C 20:1 and high levels of n-3 PUFAs [12]. The results obtained in our study shown differences in species: C20:1 level is low and ranged from $1.34 \%$ for turbot 
and garfish to $2.06 \%$ for red mullet. This result confirms the peculiarity of the Black Sea basin.

\subsubsection{Polyunsaturated fatty acid}

Significant variations were observed in PUFAs groups between species. Turbot presented highest PUFA value (36.83\%), followed by garfish $(33.45 \%)$ while red mullet have lowest amount $(21.40 \%)$. PUFA content of analyzed fish was in agreement with previously literature data. Prato et al. and Polat et al. reported similar finding for Mediterranean red mullet that presented lowest PUFA values ranged from $17.32 \%$ to $27.6 \%[13,18]$. Guner at al. and Bayir et al. were finding for garfish PUFAs amounts from $29.63 \%$ to $48 \%$ and our results are within these levels [11,16]. Only Ozogul et al. showed information about FA composition of turbot but PUFA results were higher than our amounts [14].

In our investigations important long-chain fatty acids such as eicosapentaenoic acid (EPA, C20:5 n3) docosahexaenoic acid (DHA, 22:6 n-3), linoleic acid (LA, C18:2 n-6), arahidonic acid (ARA, C20:4 n-6) and alpha-linolenic FA were found in significant levels.

The DHA was found to be the most dominant fatty acid in all PUFA's groups. The highest obtained values of DHA are for garfish $(18.51 \%)$ and turbot $(14.86 \%)$ whereas red mullet have lowest levels $(7.01 \%)$. These results were similar in comparison with Saglik et al. investigations [19]. They have analyzed the n-3 FA in Turkish wild seawater fishes (Bluefish, European anchovy) and reported that EPA and DHA occur in high amounts mostly in this fish species. In present study in both species - garfish $(1.33 \%)$ and red mullet $(1.15 \%)$ EPA levels were found lower compared to ARA levels $(\mathrm{P}<0.001)$ which were observed in red mullet $(5.11 \%)$ in second order in PUFAs group. Turbot showed the highest EPA levels $(4.60 \%)$ in all analyzed species. The results presented in Table 3 indicate that garfish and turbot were characterized by high level of n-3 FA series and low level of $n-6$ series whereas red mullet had the most balanced contents.

Fish are unable to synthesize any fatty acids of the n-6 and n-3 series unless a precursor with this omega FA structure is presented in the diet. The ability to elongate and desaturate fatty acids is not the same in all species of fish.
Table 3. Sum of $n-3$ and $n-6, n-6 / n-3$ and PUFA/SFA ratios

\begin{tabular}{|l|r|r|r|}
\hline Parameter & $\begin{array}{r}\text { Red } \\
\text { mullet }\end{array}$ & Turbot & Garfish \\
\hline$\Sigma \mathrm{n}-3$ & $10.25 \pm 1.20^{\mathrm{a}}$ & $22.72 \pm 0.90$ & $23.55 \pm 1.30^{\mathrm{a}}$ \\
\hline$\Sigma \mathrm{n}-6$ & $10.73 \pm 1.10^{\mathrm{a}}$ & $12.40 \pm 0.72^{\mathrm{a}}$ & $7.50 \pm 0.70^{\mathrm{a}}$ \\
\hline $\mathrm{n}-6 / \mathrm{n}-3$ & 1.05 & 0.55 & 0.35 \\
\hline PUFA/SFA & 0.60 & 0.94 & 0.80 \\
\hline
\end{tabular}

${ }^{\mathrm{a}}$ Significance level is $\mathrm{P}<0.001$

The turbot was able to desaturate and elongate only $3-15 \%$ of $18: 1 n-9,18: 2 n-6$ or $18: 3 n-3$ therefore in the rainbow trout, $70 \%$ of the label from 18:3 n-3 was found in 22:6 n-3 (FAO) [3].

These results agree with those obtained in other studies [13, 16, 18, 19]. Garfish and turbot were found to be the riches source of n-3 fatty acids and that is why these species can serve as a valuable source of essential n-3 fatty acids especially DHA. The total sum of n- 6 acids series sowed apparent difference between red mullet and other two species $(\mathrm{P}<0.05)$.

The $n-6 / n-3$ ratio has been suggested to be an useful indicator for comparing the relative nutritional value of fish. The ratio $0.2-1.0$ would constitute a healthy human diet [20]. That ratio was in the recommended level for two fish species. The highest $n-6 / n-3$ ratio was found to be 1.05 for red mullet followed by 0.55 for turbot and 0.35 for garfish. A lot of studies recommended dietary intakes for $n-6$ and n-3 fatty acids and described the importance of reducing the $n-6$ and increasing the n3 PUFA in diet of both adults and newborns for optimal brain and cardiovascular health and function $[1,2]$.

Simopolous, Erkkila et al. reported that several studies have found inverse association of the PUFA/SFA ratios with cardiovascular diseases and suggesting that replacement of SFA with PUFA in the diet will decrease similar health problems [1, 21]. In our study the PUFA/SFA ratio was found lower than one in all analyzed species. Ozogul at al. reported a ratio higher than 1 for species from Black Sea whereas Saglik and Imre presented similar results for fish species from Turkey [14, 19]. PUFAs 
content reported for investigated Black Sea fish species were in agreement with the average longchain fatty acids (DHA, EPA, ARA) values presented for these fish species in scientific literature [13-16,19].

In Bulgaria, people have a relatively low intake of n-3 compared with n-6 PUFA [4]. By combining a lower intake of $n-6$ fatty acids with a higher intake of n-3 fatty acids, e.g. through the consumption of seawater fish, a relatively significant effect will be achieved.

\section{Conclusions}

The results of this study indicate that turbot (Psetta maxima), red mullet (Mullus barbatus ponticus) and garfish (Belone belone) have low and moderate lipid content. In turbot and garfish SFA was the dominant FA group whereas red mullet presented highest level of MUFA. Fish species from the Black Sea coast have relatively high proportion of n-3 highly PUFA because DHA was found to be the most dominant fatty acid in all PUFA's groups. Other important n-3 PUFA - EPA was also found in significant levels (especially in turbot).

Regarding to the lipid contents, DHA and EPA levels, n-6/n-3 and PUFA/SFA ratios we may conclude that these Black Sea fish species could be considered as a source of high quality fatty acids and have good nutritional quality.

\section{Acknowledgments}

This study was financed by the National Science Fund, Ministry of Education and Science of Bulgaria (Project DVU 440/2008)

\section{References}

*E-mail: albenamerdjanova@mu-varna.bg

[1]. A. Simopoulos and L. Cleland. World Rev Nutr Diet. Basel, Karger, 92, 1-22 (2003).

[2]. K. Etherton, D. Taylor, S. Yu-Poth, P. Huth, K. Moriarty and V. Fishell, Am J Clin Nutr, 71, 1795-1885 (2000).

[3]. FAO /WHO Scientific and ethical challenges in agriculture to meet human needs (2005)
http://www.fao.org/docrep/003/X8576M/x8576 m05.htm

[4]. ***Health of the Nation Report. Doclad zdrave na nacia 2009.pdf http://ncphp.government.bg

[5]. V. Shlyakhov and G. Daskalov, The State of marine living resources Chapter $9 \mathrm{http}: / / \mathrm{www}$. blacksea-commission.org/_publ-SOE 2009CH9.asp.

[6]. B. Zorica and V. Čikeskec, Acta Adriat., 52 (2) 269 - 278 (2011).

[7]. E. Bligh, and W. Dyer, Canadian Journal of Biochemistry and Physiology, 37, 913-917 (1959).

[8]. *** BDS EN ISO 5509 (2000)

[9] *** BDS EN ISO 5508 (2004)

[10]. J. Sargent, D. Tocher, J.Bell, Fish nutrition, 4 181-257 (2002).

[11].S. Guner, B. Dincer, N. Alemdag, A. Colak, and M.Tufekci, J. Sci Food Agric, 78, 337-342 (1998).

[12]. R. Tanakol, Z. Yazici, E. Sener and E. Sencer, Lipids 34, 291-297 (1999).

[13] A. Polat, S. Kuzu and G. Özyurt. Journal of Muscle Foods, 20, 70-78, (2009).

[14]. Y. Özogul, and F. Özogul, Food Chemistry, 100, 1634-1638 (2007).

[15]. H. Lago, Pena J.and S. Aubourg, Grasas y Aceites 61 (3), 312-320 (2010).

[16]. A. Bayır, H. Haliloglu, A. Sirkecioglu, R. Mevlüt Journal of the Science of Food and Agriculture 86 (1) 163-168 (2006)

[17]. M. Stancheva, A. Merdzhanova, D. A. Dobreva and L. Makedonski, Ovidius University Annals of Chemistry 21, 23-28 (2010).

[18] E. Prato and F. Biandolino, Food Chemistry 131, 1233-1239 (2012).

[19]. S. Saglik and S. Imre, J. of Food Science, 66, 210-212 (2001).

[20]. ***HMSO, UK. Nutritional aspects of cardiovascular disease (report on health No. 46). London: HMSO (1994).

[21]. A. Erkkila, V. de Mello, U. Risirus, D. Laaksonen, Progress in Lipid Research, 47 (3), 172-187 (2008).

Submitted: March $1^{\text {th }} 2012$

Accepted in revised form: April $18^{\text {th }} 2012$ 